\title{
An Enantioselective Approach to the Hetisine Alkaloids. Synthesis of the 3-Methyl-1-aza-tricyclo[5.2.1.03,8]decane Core via Intramolecular Dipolar Cycloaddition
}

\author{
Kevin M. Peese and David Y. Gin ${ }^{*}$ \\ Department of Chemistry, University of Illinois, Urbana, IL 61801
}

\begin{abstract}
An efficient, enantioselective approach to the hetisine class of the $\mathrm{C}_{20}$-diterpenoid alkaloids is described. The strategy involves an intramolecular oxidopyridinium dipolar cycloaddition as the key transformation, in which simultaneous formation of the C5-C6 and C10-C20 bonds in the 3-methyl-1aza-tricyclo[5.2.1.0 $\left.0^{3,8}\right]$ decane core of the hetisine alkaloids is effected.
\end{abstract}

The $\mathrm{C}_{20}$-diterpenoid alkaloids isolated from the Aconitum, Delphinium, Consolida, and Spiraea species comprise a diverse family of compounds among which the atisane class of alkaloids (1) is a principal constituent. ${ }^{1}$ This class of compounds is in turn composed of several structural subclasses of alkaloids, exhibiting varied degrees of structural complexity and pharmacological activity. The hetisine class of alkaloids is among the most structurally complex subgroup of this family and is exemplified by kobusine (2), ${ }^{2}$ incorporating additional $\mathrm{C} 14-\mathrm{C} 20$ and N-C6 linkages relative to the atisane skeleton. ${ }^{3}$ Kobusine was among the earliest reported hetisine alkaloids, and it, together with several of its C15-O-acyl derivatives, has recently been shown to exhibit potent vasodilating activity in vivo. ${ }^{4}$

Although the structure of the hetisine alkaloids have been known for more than 40 years, synthetic investigations into these natural products have been rather sparse due to the formidable challenges in constructing the 3-methyl-1-aza-tricyclo[5.2.1. $\left.0^{3,8}\right]$ decane substructure (3, Scheme 1) embedded within the diterpene-derived carbon scaffold. To this end, a few creative racemic approaches to the construction of bridged aza-bicyclo substructures of the hetisine alkaloids have been reported. ${ }^{5}$ Model structures of the aza-tricyclo core have also been accessed via late-stage stepwise formation of the $\mathrm{C}-\mathrm{N}$ bonds on a suitably derivatized polycyclic carbon skeleton, ${ }^{6}$ with the latter efforts culminating in a recent synthesis of $( \pm)$ nominine in a 40 -step sequence. ${ }^{7}$ However, the notable paucity of efficient asymmetric strategies to the aza-tricyclo core $\mathbf{3}$, characteristic of all hetisine alkaloids, led us to consider the preparation of this substructure via simultaneous formation of the C5-C6 and C10-C20 bonds with the intramolecular combination of an appropriate aza-dipole and dipolarophile $(3 \Rightarrow 4)$.

Initial investigations into the feasibility of the strategy involved the use of an oxidopyridinium betaine as a relatively stable endocyclic aza-dipole ${ }^{8}$ tethered to a 2-enenitrile dipolarophile in a dipole-HOMO-controlled cycloaddition (Scheme 2). Preparation of the cycloaddition precursor commenced with 1,4-addition of cyanide to 3-methylcyclohex-2-enone (5) with $\mathrm{Et}_{2} \mathrm{AlCN}$. The putative aluminum enolate was then activated in situ with cesium fluoride and subsequently trapped with $\mathrm{Tf}_{2} \mathrm{O}$ to give the vinyl triflate $\mathbf{6}$ in $69 \%$ yield. Reduction of the nitrile 
in 6 to the corresponding aldehyde with DIBAL-H (82\%) followed by immediate reductive amination with furfurylamine provided furanyl amine 7 (99\%). Palladium catalyzed cyanation $^{9}$ of the enol triflate in 7 proceeded in $75 \%$ yield and was followed by $\mathrm{Br}_{2}-\mathrm{mediated}$ oxidative rearrangement of the furan moiety 10 to afford oxidopyridinium ylide 9 in $65 \%$. Heating the oxidopyridinium in a variety of solvents to effect dipolar cycloaddition on the C5C10 dipolarophile (10) was, however, unsuccessful as direct intramolecular conjugate addition of the oxidopyridinium nucleophile to C5 (11) was the dominant reaction manifold, affording the racemic tricyclic oxidopyridinium betaine 12 (73\%).

While the formation of $\mathbf{1 2}$ in and of itself constitutes a novel approach to the preparation of highly substituted indolizinium heterocycles, ${ }^{11}$ the suppression of direct 1,4 -addition is critical to the construction of the hetisine azatricyclic core. This led to the consideration of a new cycloaddition substrate in which a removable electron-deficient auxiliary $(Z)$ is introduced at $\mathrm{C} 5$ rather than at $\mathrm{C} 10$ of the dipolarophile to favor the cycloaddition manifold (13, Scheme 3$)$. The undesired direct conjugate addition pathway with this substrate would involve nucleophilic addition into the $\mathrm{C} 10$-position (i.e., $\mathbf{1 4} \rightarrow \mathbf{1 5}$ ). This process is likely to experience enhanced nonbonding interactions with the necessary positioning of both the $\mathrm{C} 1$ - and $\mathrm{C} 2$-methylene groups directly over the oxidopyridinium ring in the formation of the unwanted bridged azabicyclo[3.3.1] nonane oxidopyridinium 15.

To evaluate this hypothesis, preparation of the new cycloaddition precursor 22 proceeded in a sequence that is also readily amenable to asymmetric induction (Scheme 4). Asymmetric $\alpha-$ methylation of 2-oxo-cyclohexanecarboxylic acid ethyl ester (16) via its corresponding $(S)$ - $t$ butylvaline enamine derivative ${ }^{12}$ provided the $\alpha, \alpha$-disubstituted cyclohexanone 17 in $53 \%$ (98:2 er). Dehydrative condensation of $\mathbf{1 7}$ with thiophenol produced vinyl sulfide $\mathbf{1 8}$ in $93 \%$ yield to install the $\pi$-system of the dipolarophile. Reduction of the ethyl ester within $\mathbf{1 8}$ to the alcohol with DIBAL-H (99\%) followed by oxidation with IBX afforded the aldehyde 19 in 95\% yield. Oxidation of the vinyl sulfide with $m$ CPBA (94\%) allowed for the introduction of the dipolarophile activating group at C5 in the form of an aryl sulfone. Reductive amination of aldehyde 20 with furfuryl amine afforded the furanyl amine 21 (91\%), which underwent facile oxidative rearrangement with bromine in aqueous acetic acid to produce oxidopyridinium betaine 22 in $77 \%$ yield. Heating of 22 in toluene $(0.05 \mathrm{mM})$ at reflux produced the cycloadduct $\mathbf{2 3}$ in $70 \%$ yield with no evidence of products arising from simple conjugate addition (i.e., 15). Initial structure determination of the cycloadduct $\mathbf{2 3}$ came from a battery of NMR data ( $\left.{ }^{1} \mathrm{H}, \mathrm{COSY}, \mathrm{HMQC}\right)$ including an observed nOe between the C4-methyl group and the C6- angular proton, data consistent with a regioselective dipole-HOMOcontrolled cycloaddition. Structure verification of the cycloadduct ultimately came from single crystal X-ray analysis. Conjugate reduction of $\mathbf{2 3}$ and subsequent triflation of the transient enolate with $\mathrm{PhNTf}_{2} 13$ yielded the corresponding vinyl triflate $(70 \%)$, which was reduced to the alkene 24 with formic acid and $\mathrm{PdCl}_{2}\left(\mathrm{PPh}_{3}\right)_{2}(84 \%) .{ }^{14}$ Finally, desulfurization of the C5sulfone to form 25 proceeded in $82 \%$, demonstrating that this dipolarophile activating auxiliary can be removed without rearrangement or $\beta$-elimination in the newly constructed aza-tricylcic skeleton.

In summary, the first asymmetric synthesis of the 3-methyl-1-aza-tricyclo[5.2.1.0 $\left.0^{3,8}\right]$ decane core of the hetisine alkaloids is reported. The strategy involves an intramolecular oxidopyridinium dipolar cycloaddition as the key transformation in which simultaneous formation of the C5-C6 and C10-C20 bonds is effected. The facile preparation of (+)-25 clearly demonstrates feasibility of this approach and holds promise for the efficient asymmetric synthesis of the hetisine class of alkaloids. 


\section{Supplementary Material}

Refer to Web version on PubMed Central for supplementary material.

\section{Acknowledgment}

This research was supported by the NIH (GM67659). A Pharmacia (Pfizer) predoctoral fellowship to KMP is acknowledged.

\section{References}

1. Wang, F-P.; Liang, X-T. The Alkaloids. Cordell, GA., editor. Vol. 59. San Diego, CA: Academic Press; 2002. p. 1-280.

2. Suginome H, Shimanouti F. Justus Liebigs Ann. Chem 1940;545:220-228.

3. (a) Okamoto T. Chem. Pharm. Bull 1959;7:44-49. (b) Pelletier SW, Wright LH, Newton MG, Wright H. J. Chem. Soc., Chem. Commun 1970:98-99. (c) Sakai S, Yamamoto I, Yamaguchi K, Takayama H, Ito M, Okamoto T. Chem. Pharm. Bull 1982;30:4579-4584. (d) Ulubelen A, Desai HK, Srivastava SK, Hart BP, Park J, Joshi BS, Pelletier SW, Mericli AH, Mericli F, Ilarslan R. J. Nat. Prod 1996;59:360-366. [PubMed: 8699181]

4. (a) Wada K, Ishizuki S, Mori T, Bando H, Murayama M, Kawahara N. Biol. Pharm. Bull 1997;20:978982. [PubMed: 9331980] (b) Wada K, Ishizuki S, Mori T, Fujihira E, Kawahara N. Biol. Pharm. Bull 1998;21:140-146. [PubMed: 9514608] (c) Wada K, Ishizuki S, Mori T, Fujihira E, Kawahara N. Biol. Pharm. Bull 2000;23:607-615. [PubMed: 10823674]

5. (a) van der Baan JL, Bickelhaupt F. Recl. Trav. Chim. Pays-Bas 1975;94:109-112. (b) Kwak Y, Winkler JD. J. Am. Chem. Soc 2001;123:7429-7430. [PubMed: 11472177] (c) Williams CM, Mander LN. Org. Lett 2003;5:3499-3502. [PubMed: 12967309]

6. (a) Shibanuma Y, Okamoto T. Chem. Pharm. Bull 1985;33:3187-3194. (b) Muratake H, Natsume M. Tetrahedron Lett 2002;43:2913-2917.

7. Muratake H, Natsume M. Angew. Chem., Int. Ed 2004;43:4646-4649.

8. (a) Katritzky AR, Takeuchi Y. J. Am. Chem. Soc 1970;92:4134-4136. (b) Dennis N, Katritzky AR, Takeuchi Y. Angew. Chem., Int. Ed. Engl 1976;15:1-9. [PubMed: 814844] (c) Joshi RA, Ravindranathan T. Ind. J. Chem B 1984;23:300-302. (d) Katritzky AR, Dennis N. Chem. Rev 1989;89:827-861. (e) Jung ME, Longmei Z, Tangsheng P, Huiyan Z, Yan L, Jingyu S. J. Org. Chem 1992;57:3528-3530. (f) Pham VC, Charlton JL. J. Org. Chem 1995;60:8051-8055. (g) Śliwa W. Heterocycles 1996;43:2005-2029. (h) Rumbo A, Mouriño A, Castedo L, Mascareñas JL. J. Org. Chem 1996;61:6114-6120. [PubMed: 11667444] (i) Smith MP, Johnson KM, Zhang M, Flippen-Anderson JL, Kozikowski AP. J. Am. Chem. Soc 1998;120:9072-9073.

9. Yamamura K, Murahashi S. Tetrahedron Lett 1977;18:4429-4430.

10. (a) Müller C, Diehl V, Lichtenthaler FW. Tetrahedron 1998;54:10703-10712. (b) Ciufolini MA, Hermann CYW, Dong Q, Shimizu T, Swaminathan S, Xi N. Synlett 1998:105-114.

11. Shono T, Matsumura Y, Tsubata K, Inoue K, Nishida R. Chem. Lett 1983:21-24.

12. (a) Tomioka K, Ando K, Takemasa Y, Koga K. J. Am. Chem. Soc 1984;106:2718-2719. (b) Ando

K, Takemasa Y, Tomioka K, Koga K. Tetrahedron 1993;49:1579-1588.

13. Crisp GT, Scott WJ. Synthesis 1985:335-337.

14. Cacchi S, Morera E, Ortar G. Tetrahedron Lett 1984;25:4821-4824. 


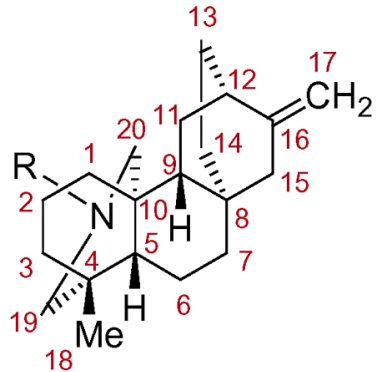

Atisane Skeleton (1)

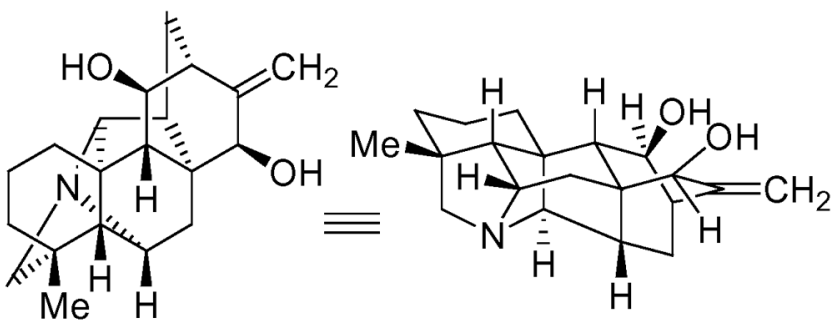

Hetisine Skeleton: Kobusine (2)

Figure 1.

Atisane and hetisine alkaloids. 

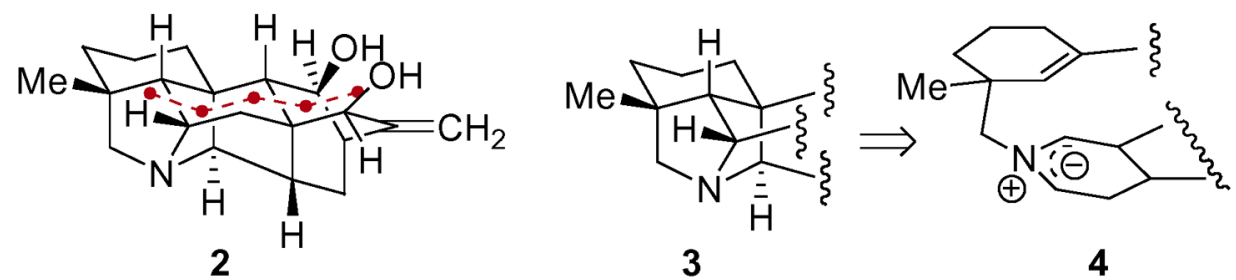

Scheme 1. 
<smiles>CC1=CC(=O)CCC1</smiles><smiles>CCO[Mg]O[Mg]</smiles><smiles>CCOC1=CC(C)(C#N)CCC1</smiles>

1) DIBAL-H, $0^{\circ} \mathrm{C}, 82 \%$

2) furfurylamine $\cdot \mathrm{HCl}, \mathrm{NEt}_{3}$, $3 \AA \mathrm{ms}$; then $\mathrm{NaBH}_{4}, 99 \%$<smiles>[R]C1=CC(C)(CNCc2ccco2)CCC1</smiles>

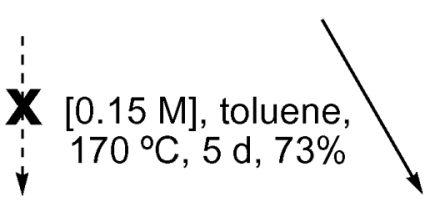

$\mathrm{KCN}, 18-\mathrm{cr}-6$, $\mathrm{Pd}\left(\mathrm{PPh}_{3}\right)_{4}$,
$75^{\circ} \mathrm{C}, 75 \%$$\quad\left(\begin{array}{ll}7 & \mathrm{R}=\mathrm{OTf} \\ 8 & \mathrm{R}=\mathrm{CN}\end{array}\right.$
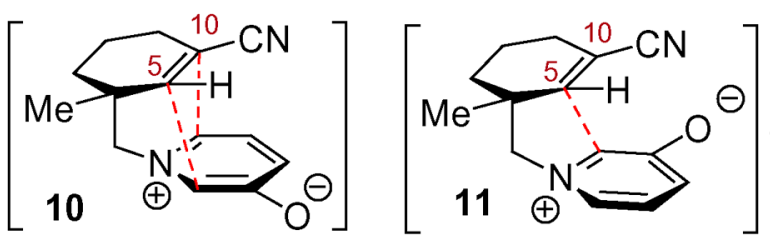

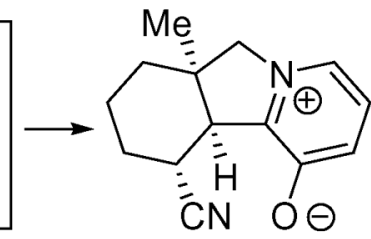

Scheme 2. 


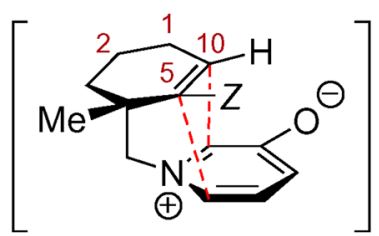

13 vs.

$$
[\mathrm{Me}
$$

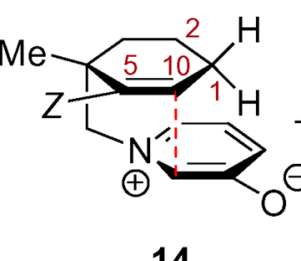

14

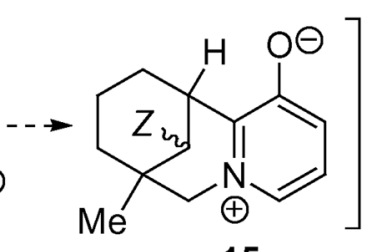

15

Scheme 3.

Org Lett. Author manuscript; available in PMC 2008 December 4. 

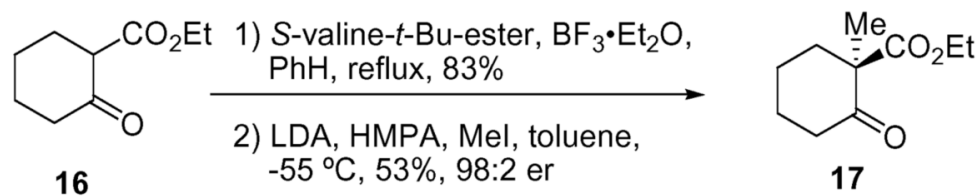

16 $55^{\circ} \mathrm{C}, 53 \%, 98: 2$ er<smiles>C[C@]1(C=O)CCCC=C1[S+]([O-])(O)Oc1ccccc1</smiles>

20

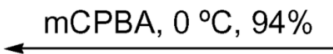

$\mathrm{PhSH}, \mathrm{P}_{2} \mathrm{O}_{5}$, $93 \%$<smiles>[R][C@]1(C)CCCC=C1[SbH2]</smiles>

1) $\mathrm{DIBAL}-\mathrm{H}, 0^{\circ} \mathrm{C}, 99 \% \quad 18 \mathrm{R}=\mathrm{CO}_{2} \mathrm{Et}$

2) IBX, DMSO, $95 \%$

furfurylamine $\bullet \mathrm{HCl}, \mathrm{NEt}_{3}$,

$3 \AA \mathrm{ms}$; then $\mathrm{NaBH}_{4}, 91 \%$<smiles>C[C@]1(CNCc2ccco2)CCCC=C1S(=O)(=O)Oc1ccccc1</smiles>

21

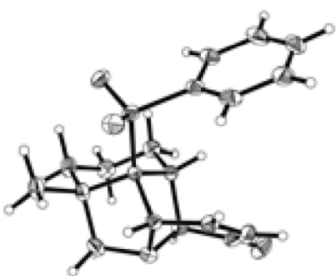

23 (X-ray)
$\mathrm{Br}_{2}, 1: 1 \mathrm{AcOH}$ :water, $0^{\circ} \mathrm{C}, 77 \%$<smiles></smiles>

[0.05 M], toluene, reflux, $70 \%$

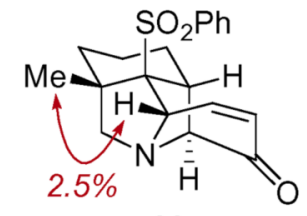

1) L-Selectride,

23

$-78^{\circ} \mathrm{C} ; \mathrm{PhNTf}_{2}, 70 \%$

2) $\mathrm{HCO}_{2} \mathrm{H}, \mathrm{NEt}_{3}$,

$\mathrm{PdCl}_{2}\left(\mathrm{PPh}_{3}\right)_{2}, 60^{\circ} \mathrm{C}, 84 \%$

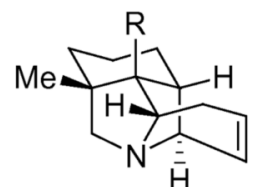

$10 \% \mathrm{Na}(\mathrm{Hg}), \mathrm{Na}_{2} \mathrm{HPO}_{4}, \quad 24 \mathrm{R}=\mathrm{SO}_{2} \mathrm{Ph}$

3:1 THF:t-BuOH, $82 \%$ 25 R = H

Scheme 4. 